\title{
Properties of $\alpha$-Chymotrypsin Covalently Immobilized on Poly(acrylic acid)-Grafted Magnetite Particles
}

\author{
Masato Shimomura, Mie Ohta, Norimiki Sugiyama, Kenji Oshima, \\ Takeshi YamauchI, and Shinnosuke MiYauCHI \\ Department of Bioengineering, Faculty of Engineering, \\ Nagaoka University of Technology, 1603-1 Kamitomioka-cho, \\ Nagaoka 940-2188, Japan
}

(Received September 2, 1998)

\begin{abstract}
Enzymatic properties of $\alpha$-chymotrypsin covalently immobilized on magnetite particles via graft polymerization of acrylic acid were investigated. Graft polymerization was carried out in a redox system consisting of mercapto groups introduced onto the surfaces of magnetite particles and ceric ions. $\alpha$-Chymotrypsin was immobilized on magnetite particles by condensation with the carboxyl groups of the grafted poly(acrylic acid). The amount of $\alpha$-chymotrypsin immobilized on $1 \mathrm{~g}$ of magnetite was $13-17 \mathrm{mg}$ and the activity of the immobilized $\alpha$-chymotrypsin (at $37^{\circ} \mathrm{C}$, pH 8.0 ) was $70 \%$ the maximum activity of the native enzyme. Due to immobilization, optimum $\mathrm{pH}$ for $\alpha$-chymotrypsin shifted to a slightly higher value, whereas optimum temperature did not change. A kinetic study of the enzymatic reaction with immobilized $\alpha$-chymotrypsin showed that the immobilization limited accessibility of substrate molecules to the active sites of the enzyme but caused little decrease of the maximum reaction rate. In water at $37^{\circ} \mathrm{C}$, immobilized $\alpha$-chymotrypsin kept $93 \%$ of its original activity over a period of 25 days, though the native enzyme was completely deactivated within 5 days by autolytic denaturalization.

KEY WORDS $\alpha$-Chymotrypsin / Poly(acrylic acid) / Magnetite / Enzyme / Immobilization / Graft Polymerization /
\end{abstract}

Enzymes have been immobilized on a variety of support materials for such practical purposes as biochemical application ${ }^{1-8}$ and biosensing. ${ }^{9-12}$ Since it is not only organic but inorganic substances that are expected as support materials, enzymes will be utilized more. If an enzyme is immobilized on particles of magnetizable substances, such as magnetite, magnetic handling of the immobilized enzyme can be performed in reactor application. However, this unique application will not come true unless efforts are made to introduce enzyme molecules onto the surfaces of inorganic materials.

The authors proposed a new technique for immobilizing enzyme molecules covalently on the surfaces of inorganic materials and applied the technique to immobilization of glucose oxidase on magnetite particles. $^{13,14}$ The immobilized glucose oxidase had $50 \%$ activity of the native enzyme and kept $95 \%$ of its original activity in water over a period of 9 months. The immobilization process included graft polymerization of acrylic acid from the surfaces of inorganic materials initiated by redox reaction between mercapto groups introduced onto the surfaces and ceric ions. Enzyme molecules were immobilized by condensation with carboxyl groups of the poly(acrylic acid) grafted onto the surfaces.

The present paper reports the covalent immobilization of $\alpha$-chymotrypsin $(\alpha-\mathrm{CT})$ on the poly(acrylic acid)grafted magnetite particles. $\alpha-\mathrm{CT}$ is a digestive enzyme which hydrolyzes peptide linkages of proteins. $\alpha$-CT is unstable in aqueous media, as it is a protein and therefore autolysis in which the enzyme hydrolyzes itself is inevitable. Provided that enzyme molecules are immobilized on a solid surface, autolysis can be avoided because interactions between the enzyme molecules decrease by immobilization. In the present study, activity and stability of the immobilized enzyme were investigated and compared with those of the native enzyme.

\section{EXPERIMENTAL}

\section{Materials}

The magnetite used was MAT-305 obtained from Toda Kogyo Corp. in the form of spherical particles. Average particle size was $0.23 \mu \mathrm{m}$ and BET surface area, $7.2 \mathrm{~m}^{2} \mathrm{~g}^{-1}$. $\alpha$-CT (EC 3.4.21.1, from bovine pancreas) was supplied by Worthington Biochemical Corp. Acrylic acid from Wako Pure Chemical Ind., Ltd. was purified by distillation under reduced pressure. 3-Mercaptopropyltrimethoxysilane (MPS) from Kanto Chemical Co., Inc. was used without further purification. Other chemicals were of guaranteed-reagent or analytical grade and used without further purification.

\section{Graft Polymerization of Acrylic Acid from Magnetite Particles}

Prior to graft polymerization of acrylic acid, the magnetite particles were treated with MPS to introduce mercapto groups onto their surfaces ${ }^{15}$ : A mixture of $3.0 \mathrm{~g}$ magnetite, $3.0 \mathrm{ml}$ MPS and $100 \mathrm{~mL}$ dried toluene was refluxed under nitrogen for $20 \mathrm{~h}$. The treated magnetite was filtered off, washed on a filter with dried toluene and then with methanol, and dried at $60^{\circ} \mathrm{C}$ in vacuo.

Graft polymerization, illustrated in Scheme 1, was carried out as follows: Into a flask, $1.0 \mathrm{~g}$ magnetite treated with MPS, $6.0 \mathrm{~g}$ acrylic acid and $20.0 \mathrm{ml}$ distilled water were charged. After deaeration of the mixture, a solution of $0.4 \mathrm{mmol}$ ceric ammonium nitrate in $6.0 \mathrm{ml} 1 \mathrm{~N}$-nitric acid was added. Polymerization was carried out at $30^{\circ} \mathrm{C}$ with stirring under nitrogen. After a given time, the polymerization was stopped with hydroquinone. The reaction mixture was diluted with distilled water and centrifuged at $10^{5} \mathrm{~ms}^{-2}$ until the magnetite particles 


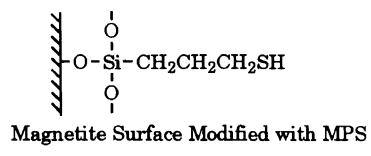

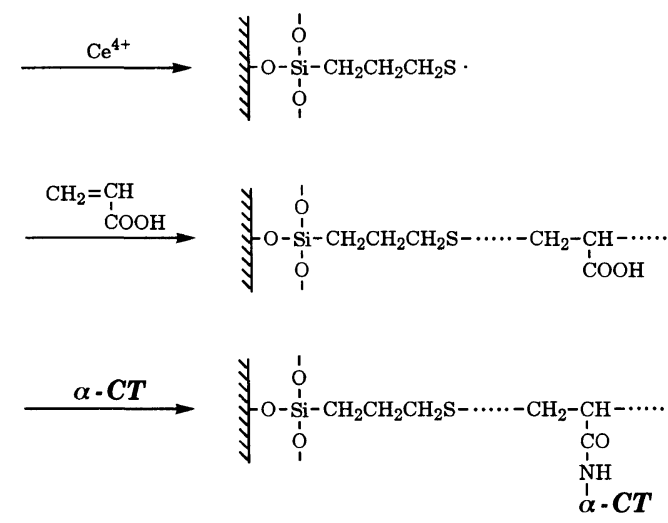

Scheme 1. Graft polymerization of acrylic acid from the surface of magnetite and immobilization of $\alpha$-CT.

completely precipitated. The precipitated magnetite particles were dispersed in distilled water and centrifuged once more. This procedure was repeated several times and the precipitated particles were dried below $60^{\circ} \mathrm{C}$ in vacuo. Attached poly(acrylic acid) was determined from weight increase of the magnetite.

\section{Immobilization of $\alpha$-CT on Magnetite Particles}

$\alpha$-CT was immobilized on magnetite particles attached to poly(acrylic acid) by condensation with carboxyl groups of the polymer as illustrated in Scheme 1. 1Cyclohexyl-3-(2-morpholinoethyl)-carbodiimide metho$p$-toluenesulfonate $(\mathrm{CMC})$ was used as a condensing agent. ${ }^{16}$

A mixture of $1.0 \mathrm{~g}$ magnetite attached to poly(acrylic acid), $34 \mathrm{mg} \alpha$-CT and $14 \mathrm{ml} 0.1 \mathrm{M}$-phosphate buffer $(\mathrm{pH} 7.5)$ was placed in a flask and stirred for $5 \mathrm{~min}$. Subsequently, $160 \mathrm{mg} \mathrm{CMC}$ was added and stirring was continued. After $18 \mathrm{~h}$ of stirring, the reaction mixture was centrifuged at $10^{5} \mathrm{~m} \mathrm{~s}^{-2}$, and the magnetite particles were completely precipitated. The precipitated particles, i.e., $\alpha$-CT-bound magnetite, were dispersed in distilled water, filtered off and washed on a filter with distilled water. This procedure was repeated several times. Immobilization and washings were conducted at $4^{\circ} \mathrm{C}$.

\section{Determination of Immobilized $\alpha-C T$}

The amount of immobilized $\alpha$-CT was estimated by analysis with Folin-Ciocalteu phenol reagent after alkaline copper treatment according to the method of Lowry. ${ }^{17}$

Beforehand, $50 \mathrm{ml} 2.0 \%$-solution of $\mathrm{Na}_{2} \mathrm{CO}_{3}$ in $0.1 \mathrm{~N}$ $\mathrm{NaOH}$ and $1.0 \mathrm{ml} 0.5 \%$-solution of $\mathrm{CuSO}_{4} \cdot 5 \mathrm{H}_{2} \mathrm{O}$ in $1.0 \%$ sodium tartrate were mixed and $2.5 \mathrm{ml}$ of the mixture was added to a suspension of $5.0 \mathrm{mg} \alpha$-CT-bound magnetite particles in $0.5 \mathrm{ml}$ distilled water. The suspension was stirred and allowed to stand for $10 \mathrm{~min}$ at room temperature. To the suspension, $0.25 \mathrm{ml}$ FolinCiocalteu phenol reagent diluted to $1 N$ in acid was added very rapidly and mixed within a second or two. After $30 \mathrm{~min}$ or longer, the magnetite particles in the suspension were filtered off, and the filtrate was ana- lyzed by spectrophotometry. Absorbance at $750 \mathrm{~nm}$ was measured on a Shimadzu UV-3100 PC spectrometer. The amount of immobilized $\alpha$-CT was calculated from a standard curve obtained with solutions of $10-150 \mu \mathrm{g}$ native $\alpha$-CT in $0.5 \mathrm{ml}$ distilled water.

\section{Measurement of $\alpha-C T$ Activity}

The activity of immobilized $\alpha$-CT was measured using $N$-benzoyl-L-tyrosine $p$-nitroanilide (BTpNA) as a substrate. $\alpha$-CT-catalyzed hydrolysis of $\mathrm{BT} p \mathrm{NA}$ was followed spectrophotometrically by measuring the rate of liberation of $p$-nitroaniline ( $p$ NA) at $385 \mathrm{~nm} .{ }^{18}$

A given amount of $\mathrm{BT} p \mathrm{NA}$ was dissolved in acetone, and $20 \mathrm{ml}$ of the acetone solution was added to $180 \mathrm{ml}$ $0.1 \mathrm{M}$-phosphate buffer. A suspension of $\alpha$-CT-bound magnetite in $4.0 \mathrm{ml}$ distilled water, containing $392 \mu \mathrm{g}$ $\alpha-\mathrm{CT}$, was mixed with $116 \mathrm{ml}$ of the buffer solution of $\mathrm{BT} p$ NA kept at a given temperature. The mixture was incubated at the given temperature, and at intervals, portions of the mixture were taken. The magnetite particles in the mixture were precipitated rapidly with a magnet, and absorbance of supernatant was measured at $385 \mathrm{~nm}$ to determine the concentration of liberated $p$ NA. Enzymatic activity was evaluated from the initial rate of liberation of $p$ NA. The activity of immobilized $\alpha-\mathrm{CT}$ was measured at a $\mathrm{pH}$ range of $6.5-9.0$ and $25-50^{\circ} \mathrm{C}$ for comparison with the native enzyme.

Spectrophotometry was conducted to measure enzymatic reaction rates at various $\mathrm{BT} p \mathrm{NA}$ concentrations. Kinetic effects of immobilization were discussed based on the results.

\section{RESULTS AND DISCUSSION}

\section{Graft Polymerization of Acrylic Acid and Immobilization} of $\alpha-C T$

Poly(acrylic acid) became attached to magnetite particles by graft polymerization of acrylic acid. The amount of attached polymer was proportional to polymerization time up to $90 \mathrm{~min}$ and the rate of attaching was $1.2 \mathrm{mg} \mathrm{min}^{-1}$ on $1 \mathrm{~g}$ magnetite. After polymerization for $90 \mathrm{~min}, 23 \%(1.4 \mathrm{~g})$ of the monomer was converted to polymer and attached polymer was less thus than $10 \%$ the produced polymer. The formation of unattached polymer was due to chain transfer of growing polymer radicals. These results are consistent with the data published previously. ${ }^{14}$

Table I shows amounts of $\alpha$-CT immobilized on the magnetite particles attached to poly(acrylic acid). The amount of $\alpha$-CT immobilized on $1 \mathrm{~g}$ magnetite particles was $13-17 \mathrm{mg}$, hardly depending on poly(acrylic acid) content on the magnetite surface. Taking the molecular weight of $\alpha$-CT (25000) into account, the number of $\alpha$-CT molecules immobilized on $1 \mathrm{~g}$ magnetite is calculated to be from $3.1 \times 10^{17}$ to $4.1 \times 10^{17}$. Packing density near $2.2 \times 10^{-3} \mathrm{~nm}^{3}$ dalton $^{-1}$ is commonly observed for such globular proteins as enzymes ${ }^{19-21}$ and, therefore, one molecule of $\alpha$-CT can be estimated to occupy a volume of $55 \mathrm{~nm}^{3}$. If $\alpha$-CT molecules are spherical and magnetite particles are covered with close-packed monolayers of $\alpha$-CT molecules, the number of $\alpha$-CT molecules on $1 \mathrm{~g}$ magnetite is $3.8 \times 10^{17}$. This value is consistent with the experimental data. Thus, it 
Table I. Attached polymer and immobilized $\alpha$-CT

\begin{tabular}{|c|c|c|c|}
\hline \multirow{3}{*}{ Sample } & \multicolumn{2}{|c|}{ Graft polymerization } & \multirow{2}{*}{$\begin{array}{c}\alpha-\mathrm{CT} \text { immobilization } \\
\alpha-\mathrm{CT} \text { immobilized } \\
\text { on } 1 \mathrm{~g} \text { magnetite }\end{array}$} \\
\hline & Polymerization time & $\begin{array}{l}\text { Poly(acrlyric acid) attached } \\
\text { onto } 1 \mathrm{~g} \text { magnetite }\end{array}$ & \\
\hline & $\min$ & $\mathrm{mg}$ & $\mathrm{mg}$ \\
\hline 1 & 20 & 25.0 & 12.8 \\
\hline 2 & 25 & 28.0 & 14.6 \\
\hline 3 & 30 & 36.3 & 13.7 \\
\hline 4 & 40 & 44.6 & 16.9 \\
\hline
\end{tabular}

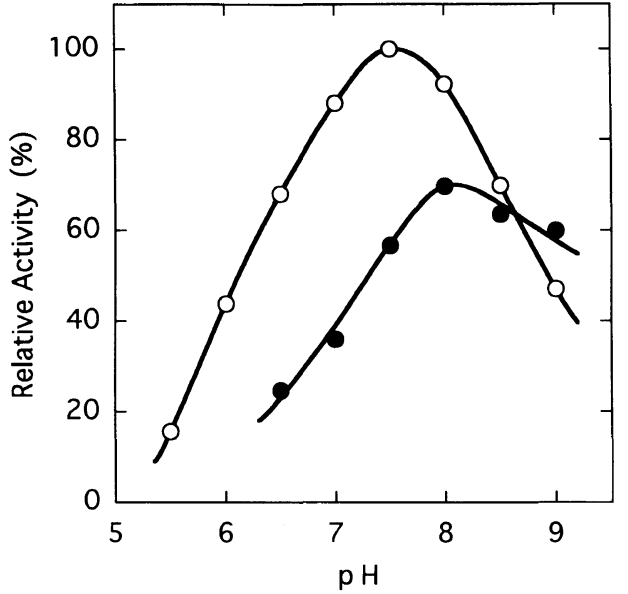

Figure 1. Effects of $\mathrm{pH}$ on activity of $\alpha-\mathrm{CT}$ : (O) native, immobilized on magnetite. Activity was measured at $37^{\circ} \mathrm{C}$. The concentrations of $\alpha-\mathrm{CT}$ and BTpNA were $3.27 \mathrm{mgl}^{-1}$ and $97.8 \mu \mathrm{M}$, respectively.

is likely that magnetite particles are nearly covered with close-packed monolayers of $\alpha$-CT. However, whether all immobilized $\alpha$-CT molecules are present in monolayers is a matter for argument, since stacking of $\alpha$-CT molecules can result from condensation of $\alpha$-CT molecules.

\section{Effects of $p H$ and Temperature on Activity of $\alpha-C T$ Immobilized on Magnetite Particles}

The activity of immobilized $\alpha$-CT was compared with that of the native one at various $\mathrm{pH}$ and temperatures. The $\alpha$-CT-bound magnetite dealt in the following results and discussion is essentially identical with Sample 3 in Table I.

The effects of $\mathrm{pH}$ on the activitiy of the native and immobilized $\alpha$-CT are shown in Figure 1, where the ratio of initial rate of hydrolisis of BT $p$ NA by the native or immobilized $\alpha$-CT to that of the hydrolysis by the native $\alpha-\mathrm{CT}$ at $\mathrm{pH} 7.5$ is given as relative activity. The activity of immobilized $\alpha$-CT at $\mathrm{pH} 8.0$ was $70 \%$ the maximum activity of the native one. It should be noted that optimum $\mathrm{pH}$ for the native $\alpha$-CT was between 7.0 and 8.0 , whereas that for the immobilized $\alpha$-CT was in the vicinity of 8.0 . This shift of optimum $\mathrm{pH}$ by immobilization can be attributed to the influence of remaining carboxyl groups of poly(acrylic acid) attached to the magnetite particles as discussed for immobilized glucose oxidase, ${ }^{14}$ i.e., the shift of optimum $\mathrm{pH}$ can be regarded as equivalent to canceling acidity due to remaining carboxyl groups.

The effects of temperature on the activity of the native

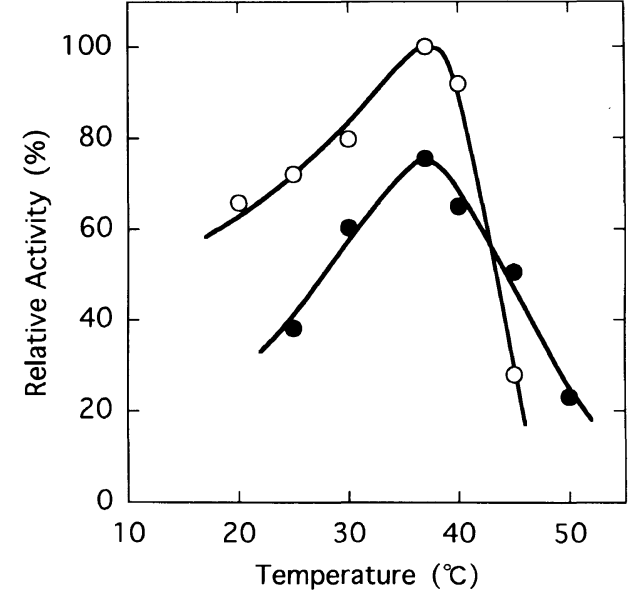

Figure 2. Effects of temperature on activity of $\alpha$-CT: $(O)$ native, immobilized on magnetite. Activity was measured at $\mathrm{pH}$ 8.0. The concentrations of $\alpha-\mathrm{CT}$ and BT $p$ NA were $3.27 \mathrm{mgl}^{-1}$ and $97.8 \mu \mathrm{M}$, respectively.

and immobilized $\alpha$-CT are shown in Figure 2. The relative activity is given as the ratio of activity of the native or immobilized $\alpha-\mathrm{CT}$ to that of the native $\alpha-\mathrm{CT}$ at $37^{\circ} \mathrm{C}$. Optimum temperature was observed between 35 and $40^{\circ} \mathrm{C}$ for both the native and immobilized $\alpha-\mathrm{CT}$. Above $45^{\circ} \mathrm{C}$, the activity of immobilized $\alpha$-CT was higher than that of the native one. The same was noted for immobilized glucose oxidase. ${ }^{14}$

On the other hand, $\alpha$-CT-bound magnetite, with $\alpha$-CT content of $5.1 \mathrm{mgg}^{-1}(37 \%$ of Sample 3 in Table I), was prepared by immobilization reaction for $5 \mathrm{~h}$. Specific activity of the immobilized $\alpha-\mathrm{CT}$ was found to be nearly equal to that of Sample $3(103 \%$ of Sample 3$)$ at $37^{\circ} \mathrm{C}$, pH 8.0.

\section{Kinetic Effects of Immobilization}

To study the kinetic effects of immobilization, the rates of hydrolysis of BTpNA by the native and immobilized $\alpha-\mathrm{CT}$ were measured at various BT $p$ NA concentrations. Figure 3 shows typical time courses of hydrolysis of BT $p$ NA by the native and immobilized $\alpha$-CT.

The hydrolysis of BT $p$ NA by $\alpha-C T$ is assumed to proceed through Michaelis-Menten mechanism as

$$
\mathrm{E}+\mathrm{S} \underset{k_{2}}{\stackrel{k_{1}}{\rightleftarrows}} \mathrm{ES} \stackrel{k_{3}}{\longrightarrow} \mathrm{E}+\mathrm{P}
$$

with hydrolysis rate 


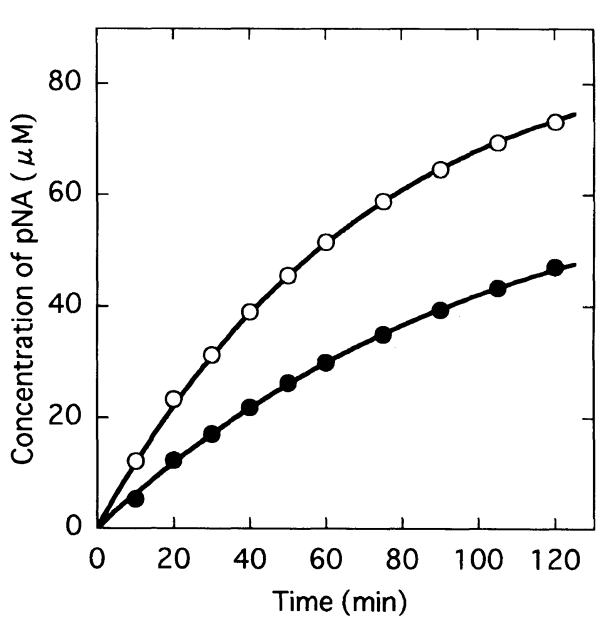

Figure 3. Typical time courses of hydrolysis of BTpNA by $\alpha-\mathrm{CT}$ : (O) native, (O) immobilized on magnetite. Hydrolysis was followed at $37^{\circ} \mathrm{C}, \mathrm{pH}$ 8.0. The concentrations of $\alpha$-CT and BT $p$ NA were $3.27 \mathrm{mg}^{-1}$ and $97.8 \mu \mathrm{M}$, respectively.

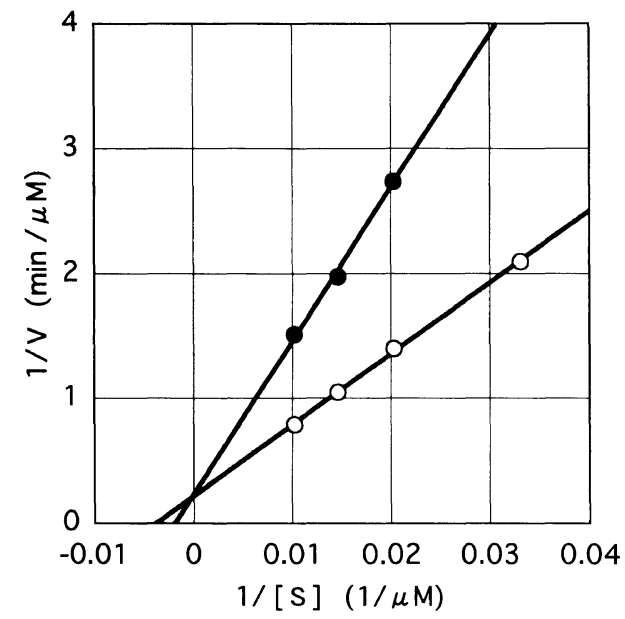

Figure 4. Lineweaver-Burk plots of the hydrolysis of BTpNA (at $\left.37^{\circ} \mathrm{C}, \mathrm{pH} 8.0\right)$ by $\alpha-\mathrm{CT}$ : $(\bigcirc)$ native; $(\circlearrowleft)$ immobilized on magnetite.

$$
\begin{aligned}
& V=V_{\max }[\mathrm{S}] /\left(K_{\mathrm{m}}+[\mathrm{S}]\right) \\
& \quad V_{\text {max }}=k_{3}[\mathrm{E}]_{0}, \quad K_{\mathrm{m}}=\left(k_{2}+k_{3}\right) / k_{1}
\end{aligned}
$$

where $\mathrm{E}, \mathrm{S}, \mathrm{ES}$, and $\mathrm{P}$ represent the enzyme $(\alpha-\mathrm{CT})$, substrate (BTpNA), enzyme-substrate complex and product ( $p \mathrm{NA}$ ), respectively; $[\mathrm{E}]_{0}$ is an initial concentration of the enzyme; rate constants are given as $k_{1}, k_{2}$, and $k_{3}$. The reciprocal of rate $V$ is

$$
1 / V=\left(K_{\mathrm{m}} / V_{\max }\right) /[\mathrm{S}]+1 / V_{\max }
$$

which means that plots of $1 / V$ against $1 /[\mathrm{S}]$ (Lineweaver-Burk plots) give a straight line, and intercepts on the $1 / V$ axis and $1 /[\mathrm{S}]$ axis give $1 / V_{\max }$ and $-1 / K_{\mathrm{m}}$, respectively. Based on the initial rates of hydrolysis at various $\mathrm{BT} p \mathrm{NA}$ concentrations, $1 / V$ is plotted against $1 /[\mathrm{S}]$ for the native and immobilized $\alpha-\mathrm{CT}$ in Figure 4. The plots give straight lines of typical Michaelis-Menten form.

The maximum reaction rates $V_{\max }$ and apparent Michaelis constants $K_{\mathrm{m}}$ determined from Figure 4 are presented in Table II. $K_{\mathrm{m}}$ for $\alpha$-CT immobilized on magnetite particles was larger than that for native $\alpha-\mathrm{CT}$. The larger $K_{\mathrm{m}}$ for immobilized $\alpha$-CT suggests decrease
Table II. Kinetic parameters for native and immobilized $\alpha-\mathrm{CT}$ at $37^{\circ} \mathrm{C}, \mathrm{pH} 8.0$

\begin{tabular}{lcc}
\hline \multirow{2}{*}{$\alpha-\mathrm{CT}$} & $V_{\max }$ & $K_{\mathrm{m}}$ \\
\cline { 2 - 3 } & $\mu \mathrm{M} \mathrm{min}^{-1}$ & $\mu \mathrm{M}$ \\
\hline Native & 4.6 & 260 \\
Immobilized & 4.3 & 530 \\
\hline
\end{tabular}

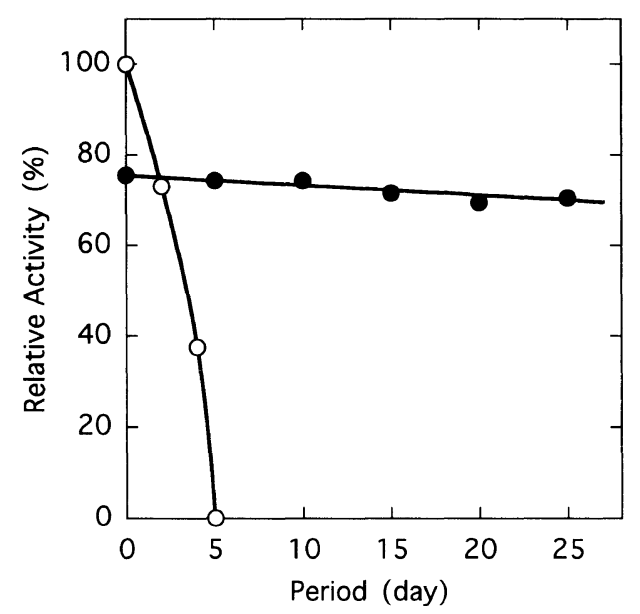

Figure 5. Stability of $\alpha-\mathrm{CT}$ : (O) native; (O) immobilized on magnetite.

in the rate constant $k_{1}$ due to limited accessibility of $\mathrm{BT} p$ NA molecules to active sites of immobilized $\alpha-\mathrm{CT}$. Decrease in $k_{1}$ may be associated with conformational changes of $\alpha-\mathrm{CT}$ molecules caused by immobilization. Little difference between $V_{\max }$ values of the native and immobilized $\alpha$-CTs shows that the rate constant $k_{3}$ hardly changes by immobilization.

\section{Stability of Immobilized $\alpha-C T$}

The stability of the $\alpha$-CT immobilized on magnetite particles was examined in distilled water. A mixture of $0.5 \mathrm{~g} \alpha$-CT-bound magnetite and $70 \mathrm{ml}$ distilled water, whose $\alpha$-CT concentration was $9.8 \mu \mathrm{g} \mathrm{ml}^{-1}$, was incubated at $37^{\circ} \mathrm{C}$, and the activity of immobilized $\alpha$-CT was periodically measured under optimum conditions (at $37^{\circ} \mathrm{C}, \mathrm{pH} 8.0$ ).

As shown in Figure 5, immobilized $\alpha$-CT kept $93 \%$ its original activity in water at $37^{\circ} \mathrm{C}$ over a period of 25 days, whereas native $\alpha$-CT was completely deactivated within 5 days by autolytic denaturalization. This demonstrates that the stability of digestive enzymes in aqueous media can be improved remarkably, autolysis being avoided, by immobilization.

\section{CONCLUSIONS}

$\alpha$-CT molecules were covalently immobilized on the surfaces of magnetite particles via graft polymerization of acrylic acid from the surfaces. The activity of immobilized $\alpha$-CT under optimum conditions (at $37^{\circ} \mathrm{C}$, $\mathrm{pH} 8.0$ ) was $70 \%$ the maximum activity of native $\alpha-\mathrm{CT}$. It was confirmed that, in water at $37^{\circ} \mathrm{C}$, immobilized $\alpha$-CT kept $93 \%$ its original activity over a period of 25 days, though native $\alpha$-CT was completely deactivated within 5 days by autolysis. 
By immobilization of enzymes on magnetite particles, magnetic handling or transport of the enzymes is possible in reactor application. Furthermore, it should be emphasized that the autolytic denaturalization, characteristic of digestive enzymes such as $\alpha-\mathrm{CT}$ in aqueous media, can be avoided by immobilizing enzyme molecules on solid particles.

\section{REFERENCES}

1. A. B. Patel, S. N. Pennington, and H. D. Brown, Biochim. Biophys. Acta, 178, 626 (1969).

2. J. B. Taylor and H. E. Swaisgood, Biochim. Biophys. Acta, 284, 268 (1972).

3. M. Valaris and W. J. Harper, J. Food Sci., 38, 477 (1973).

4. P. Gemeiner, C. Polak, A. Breier, and L. Petrus, Enzyme Microbiol. Technol., 8, 109 (1986).

5. S.-A. Wilson, K. Peek, and R. M. Daniel, Biotechnol. Bioeng., 43, 225 (1994).

6. W. F. Line, A. Kwong, and H. H. Weetall, Biochim. Biophys. Acta, 242, 194 (1971).

7. G. Baum, F. B. Ward, and H. H. Weetall, Biochim. Biophys. Acta, 268, 411 (1972).
8. F. Borrego, M. Tari, A. Manjon, and J. L. Iborra, Appl. Biochem Biotechnol., 22, 129 (1989).

9. C. Bourdillon, J. P. Bourgeois, and D. Thomas, J. Am. Chem Soc., 102, 4231 (1980).

10. H. M. Wu, R. Olier, N. Jaffrezic-Renault, P. Clecht, A. Nyamsi, and C. Martelet, Electrochim. Acta, 39, 327 (1994).

11. T. Tatsuma, K. Saito, and N. Oyama, Anal. Chem., 66, 1002 (1994).

12. K. Kojima, T. Yamauchi, M. Shimomura, and S. Miyauchi, Polymer, 39, 2079 (1998).

13. M. Shimomura, H. Kikuchi, H. Matsumoto, T. Yamauchi, and S. Miyauchi, Polym. J., 27, 974 (1995).

14. M. Shimomura, H. Kikuchi, T. Yamauchi, and S. Miyauchi, $J$. Macromol. Sci.-Pure Appl. Chem., A33, 1687 (1996).

15. N. Tsubokawa, K. Maruyama, Y. Sone, and M. Shimomura, Polym. J., 21, 475 (1989).

16. K. Mosbach, Acta Chem. Scand., 24, 2084 (1970).

17. O. H. Lowry, N. J. Rosebrough, A. L. Farr, and R. J. Randall, J. Biol. Chem., 193, 265 (1951)

18. H. F. Bundy, Anal. Biochem., 3, 431 (1962).

19. B. W. Matthews, J. Mol. Biol., 33, 491 (1968).

20. J. Hendle, H.-J. Hecht, H. M. Kalisz, R. D. Schmid, and D Schomburg, J. Mol. Biol., 223, 1167 (1992).

21. N. Kunishima, K. Fukuyama, S. Wakabayashi, M. Sumida, M. Takaya, Y. Shibano, T. Amachi, and H. Matsubara, Proteins: Struct., Funct., Genet., 15, 216 (1993). 